\title{
Turnover and Splanchnic Metabolism of Free Fatty Acids and Ketones in Insulin-dependent Diabetics at Rest and in Response to Exercise
}

\author{
John Wahren, Yuzo Sato, Jan Östman, \\ Lars Hagenfeldt, and Philip Felig \\ Departments of Clinical Physiology and Medicine, Huddinge \\ Hospital, Department of Clinical Chemistry, Karolinska Hospital, \\ Stockholm, Sweden; Department of Internal Medicine, Yale \\ University School of Medicine, New Haven, Connecticut
}

bstract. Nine insulin-dependent diabetics and six healthy controls were studied at rest, during, and after $60 \mathrm{~min}$ of bicycle exercise at a work load corresponding to $45 \%$ of their maximal oxygen intake. The catheter technique was employed to determine splanchnic and leg exchange of metabolites. FFA turnover and regional exchange was evaluated using $\left[{ }^{14} \mathrm{C}\right]$ oleate infusion. Basal glucose $(13.8 \pm 1.1 \mathrm{mmol} / \mathrm{l})$, ketone body $(1.12 \pm 0.12$ $\mathrm{mmol} / \mathrm{l})$, and FFA $(967 \pm 110 \mu \mathrm{mol} / \mathrm{l})$ concentrations were elevated in the diabetics in comparison with controls.

In the resting state, splanchnic ketone acid production in the diabetics was 6-10-fold greater than in controls. Uptake of oleic acid by the splanchnic bed was increased 2-3-fold, and the proportion of splanchnic FFA uptake converted to ketones $(61 \%)$ was threefold greater than in controls. In contrast, splanchnic fractional extraction of oleic acid was identical in diabetics and controls. A direct relationship was observed between splanchnic uptake and splanchnic inflow (plasma concentration $\times$ hepatic plasma flow) of oleic acid that could be described by the same regression line in the diabetic and control groups.

During exercise, splanchnic ketone production rose in both groups. In the control group the increase in ketogenesis was associated with a rise in splanchnic inflow and in uptake of oleic acid, a rise in splanchnic fractional extraction of oleate, and an increase in the proportion of splanchnic FFA uptake converted to ketone acids from

Dr. Sato's present address is Research Center of Health, Physical Fitness, and Sports, Nagoya University, Nagoya, Japan. 1984.

Received for publication 5 August 1983 and in revised form 12 January

J. Clin. Invest.

(c) The American Society for Clinical Investigation, Inc. 0021-9738/84/05/1367/10 \$1.00

Volume 73, May 1984, 1367-1376
$20-40 \%$. In the diabetic group, the increase in ketogenesis occurred in the absence of a rise in splanchnic inflow or uptake of oleic acid, but was associated with an increase in splanchnic fractional extraction of oleic acid and a marked increase in hepatic conversion of FFA to ketones, so that the entire uptake of FFA was accountable as ketone acid output. Splanchnic uptake of oleic acid correlated directly with splanchnic oleic acid inflow in both groups, but the slope of the regression line was steeper than in the resting state.

Plasma glucagon levels were higher in the diabetic group at rest and during exercise, while plasma norepinephrine showed a twofold greater increment in response to exercise in the diabetic group (to $1,400-1,500 \mathrm{pg} / \mathrm{ml}$ ). A net uptake of ketone acids by the leg was observed during exercise but could account for $<5 \%$ of leg oxidative metabolism in the diabetics and $<1 \%$ in controls.

Despite the increase in ketogenesis during exercise, a rise in arterial ketone acid levels was not observed in the diabetics until postexercise recovery, during which sustained increments to values of $1.8-1.9 \mathrm{mmol} / \mathrm{l}$ and sustained increases in splanchnic ketone production were observed at 30-60 min. The largest increment in blood ketone acids and in splanchnic ketone production above values observed in controls thus occurred in the diabetics after $60 \mathrm{~min}$ of recovery from exercise.

We conclude that: $(a)$ In the resting state, increased ketogenesis in the diabetic is a consequence of augmented splanchnic inflow of FFA and increased intrahepatic conversion of FFA to ketones, but does not depend on augmented fractional extraction of circulating FFA by the splanchnic bed. (b) Exercise-induced increases in ketogenesis in normal subjects are due to augmented splanchnic inflow and fractional extraction of FFA as well as increased intrahepatic conversion of FFA to ketones. (c) When exercise and diabetes are combined, ketogenesis 
increases further despite the absence of a rise in splanchnic inflow of FFA. An increase in splanchnic fractional extraction of FFA and a marked increase in intrahepatic conversion of FFA to ketones accounts for the exaggerated ketogenic response to exercise in the diabetic. $(d)$ Elevated levels of plasma glucagon and/or norepinephrine may account for the increased hepatic ketogenic response to exercise in the diabetic. (e) Ketone utilization by muscle increases during exercise but constitutes a quantitatively minor oxidative fuel for muscle even in the diabetic. $(f)$ The accelerated ketogenesis during exercise in the diabetic continues unabated during the recovery period, resulting in an exaggerated postexercise ketosis.

\section{Introduction}

Insulin-dependent (type I) diabetes is characterized by increased lipolysis as well as by ketosis. In recent years, a considerable body of evidence has been marshalled which demonstrates that the regulation of ketogenesis is not only influenced by the rate of lipolysis but also by the intrahepatic regulation of fatty acid oxidation (1). The evidence for this concept is largely based on studies in diabetic or fasted animals (1). With respect to studies in humans, we have recently observed that in thyrotoxicosis, increased ketogenesis is primarily a consequence of increased splanchnic delivery of FFA (augmented lipolysis and increased hepatic blood flow) rather than of altered hepatic metabolism (2). In human type I diabetics, Sestoft et al. (3) reported that ketone production is linearly related to splanchnic inflow of FFA as well as being influenced by intrahepatic events. Their data, however, are difficult to interpret. Firstly, the rate of splanchnic ketone production observed in their healthy control subjects was comparable to that of their diabetic subjects and 4-5-fold greater than we have observed in normal postabsorptive subjects (2). Secondly, those authors (3) did not use isotopically labeled fatty acids to assess splanchnic FFA exchange, thus precluding a determination of total FFA uptake by the splanchnic bed or splanchnic fractional extraction of FFA. Thirdly, rather than unchanged or increased rates of splanchnic glucose production, as would be expected in type I diabetics (4), their diabetic subjects demonstrated glucose production rates that were $40 \%$ lower than the healthy controls (3). Thus, despite the extensive animal data available (1), the importance of such factors as lipolysis, hepatic blood flow, fractional extraction of FFA by the splanchnic bed, and increased hepatic utilization of extracted fatty acids for ketogenesis, have not been established in human type I diabetes. The role of these various factors in determining ketone production in the diabetic is of interest not only in the resting state but also in response to exercise. Previous studies

1. Abbreviations used in this paper: ANOVA, analysis of variance; type I, insulin-dependent. from our laboratory (4) and others (5) have shown that exercise may increase ketogenesis in the type I diabetic. On the other hand, exercise is known to cause a reduction in hepatic blood flow $(6,7)$. Consequently, exercise provides the possibility of examining the factors influencing FFA extraction and conversion to ketones in the absence of an increase in FFA inflow to the splanchnic bed. In addition, previous studies have shown that in normal subjects blood ketones rise most during recovery from exercise (8). The effect of diabetes on this postexercise ketosis has not, however, been established.

The present study was consequently undertaken to evaluate splanchnic inflow, uptake, and fractional extraction of FFA and the relationship of these processes to hepatic ketogenesis in type I diabetics in the resting state and in response to exercise. We also examined circulating levels of FFA and ketones during a 60 -min postexercise recovery period to determine the effect of diabetes on postexercise ketosis.

\section{Methods}

Subjects. Two groups of subjects were studied at the Department of Clinical Physiology, Huddinge University Hospital. The patient group consisted of nine nonobese type I patients with diabetes mellitus of $7-23$ yr duration. The subjects received their last insulin injection (as intermediate acting insulin) 24-26 h before the study. The control group consisted of six healthy nonobese male volunteers. Clinical and laboratory data for all subjects are given in Table I. All subjects were consuming a weight-maintaining diet containing at least $200 \mathrm{~g}$ of carbohydrate per day for $3 \mathrm{~d}$ before the study. The purpose, nature, and potential risks of the study were carefully explained to all patients and control subjects before obtaining their voluntary consent to participate. The procedures used in these studies were approved by the institutional ethical committees.

Experimental protocol. The studies were performed in the morning after an overnight fast (12-14 h). Teflon catheters were inserted percutaneously into a femoral artery and a femoral vein. A Cournand catheter (No. 7-8) was introduced percutaneously into a femoral vein and manipulated under fluoroscopic control to a right-sided hepatic vein. The tip of the catheter was placed $3-4 \mathrm{~cm}$ from the wedge position. The subjects were studied in the resting state (supine), during exercise (upright sitting), and during the postexercise recovery period (supine). Exercise was performed for $60 \mathrm{~min}$ on a cycle ergometer (Siemens Elema, Sweden) at a work load set at $\sim 45 \%$ of the subjects' maximal oxygen uptake. The relative work intensities actually achieved were $46 \pm 2 \%$ in the diabetic patients and $44 \pm 1 \%$ in the healthy controls.

FFA turnover and regional exchange were determined using intravenous infusion of ${ }^{14} \mathrm{C}$-labeled oleic acid bound to human serum albumin $(0.5 \mu \mathrm{Ci} / \mathrm{min})$ at rest and during exercise (9). Constant levels of oleic acid specific activity were reached in all subjects at rest and after 30-40 min of exercise (Fig. 1). Hepatic and leg blood flow were measured using indicator dilution techniques and indocyanine green dye $(6,10$, 11). Arterial, hepatic, and femoral venous blood samples were drawn 2-3 times at 5-10-min intervals in the resting state and at 10-15-min intervals during exercise and during a 60 -min postexercise recovery period.

Analytical methods. Plasma FFA were extracted as described by Dole and Meinertz (12). FFA radioactivity was measured in the heptane 
Table I. Clinical Data for Diabetic and Control Subjects

\begin{tabular}{|c|c|c|c|c|c|c|c|c|c|}
\hline \multirow[b]{2}{*}{ Subjects } & \multirow[b]{2}{*}{ Age } & \multirow[b]{2}{*}{ Height } & \multirow[b]{2}{*}{ Weight } & \multirow[b]{2}{*}{$\begin{array}{l}\text { Maximal } \\
\text { oxygen uptake }\end{array}$} & \multirow[b]{2}{*}{$\begin{array}{l}\text { History of } \\
\text { diabetes }\end{array}$} & \multirow[b]{2}{*}{$\begin{array}{l}\text { Dose of } \\
\text { insulin* }\end{array}$} & \multicolumn{3}{|c|}{ Arterial concentration of } \\
\hline & & & & & & & Glucose & 3-Hydroxybutrate & Acetoacetate \\
\hline & $y r$ & $\mathrm{~cm}$ & $k g$ & $l / \min$ & $y r$ & IU & $\mathrm{mmol} / \mathrm{l}$ & $\mathrm{mmol} / \mathrm{l}$ & $\mathrm{mmol} / \mathrm{l}$ \\
\hline \multicolumn{10}{|c|}{ Patients } \\
\hline MK & 48 & 183 & 73 & 3.36 & 23 & 44 & 12.1 & 1.26 & 0.35 \\
\hline HL & 27 & 184 & 83 & 3.20 & 12 & $48+32$ & 15.6 & 1.73 & 0.64 \\
\hline $\mathrm{HL}$ & 39 & 181 & 65 & 2.53 & 7 & $24+16$ & 15.0 & 0.86 & 0.29 \\
\hline JB & 34 & 179 & 72 & 3.13 & 26 & $30+20$ & 10.6 & 0.71 & 0.24 \\
\hline TB & 36 & 172 & 62 & 3.43 & 16 & 48 & 15.6 & 0.66 & 0.31 \\
\hline TS & 41 & 173 & 80 & 3.19 & 15 & $52+8$ & 17.0 & 0.27 & 0.18 \\
\hline $\mathrm{CV}$ & 35 & 185 & 82 & 3.62 & 12 & $24+12$ & 15.5 & 0.25 & 0.12 \\
\hline RS & 30 & 184 & 75 & 3.40 & 7 & 16 & 6.6 & 1.24 & 0.39 \\
\hline LP & 42 & 173 & 70 & 3.03 & 15 & 28 & 16.5 & 0.31 & 0.24 \\
\hline \multicolumn{10}{|c|}{ Controls } \\
\hline GG & 33 & 189 & 93 & 3.40 & & & 4.2 & 0.04 & 0.03 \\
\hline UR & 31 & 189 & 70 & 3.29 & & & 4.4 & 0.03 & 0.04 \\
\hline HR & 25 & 174 & 64 & 3.59 & & & 4.3 & 0.03 & 0.03 \\
\hline RH & 27 & 180 & 80 & 2.94 & & & 4.2 & 0.07 & 0.06 \\
\hline NB & 31 & 186 & 90 & 3.60 & & & 4.6 & 0.02 & 0.05 \\
\hline UD & 22 & 185 & 77 & 3.40 & & & 3.8 & 0.04 & 0.04 \\
\hline
\end{tabular}

* Where two numbers are shown they represent morning and evening doses of insulin, respectively.

extract and subsequently corrected for radioactivity present in esterified fatty acids remaining in the heptane phase after extraction of the free acids into alkaline methanol. The concentrations of individual FFA were determined by gas chromatography, using heptadecanoic acid as internal standard (13). Glucose (14), 3-hydroxybutyrate, acetoacetate (15), and glycerol (16) concentrations were all determined enzymatically in whole blood. Plasma glucagon (17) and human growth hormone (18) were determined by radioimmunoassay; epinephrine and norepinephrine (19) were measured by a radioenzymatic technique.

Hematocrit was measured using a microcapillary hematocrit centrifuge and corrected for trapped plasma. $\mathrm{O}_{2}$ saturation was measured

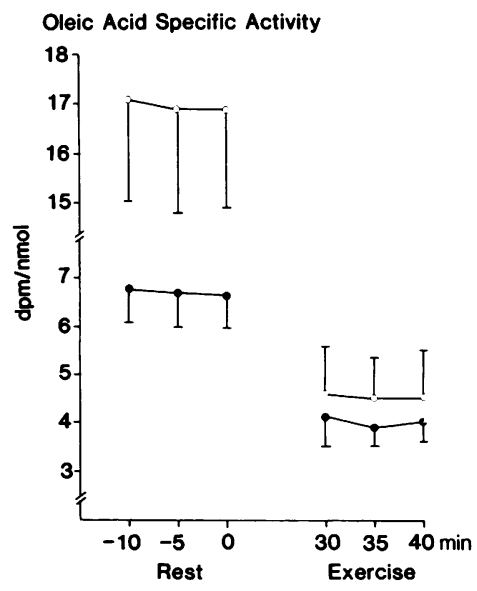

Figure 1. Oleic acid specific activity in the resting state and during exercise in diabetic patients (filled circles) and healthy controls (unfilled circles). spectrophotometrically (20) and hemoglobin was measured by the cyanmethemoglobin technic (21). Expired air was analyzed using the Scholander microtechnique.

Calculations and statistical methods. The turnover rate of oleic acid was calculated as the rate of infusion of $\left[{ }^{14} \mathrm{C}\right]$ oleic acid divided by its steady state arterial plasma specific activity. The fractional uptake (f) of oleic acid across the splanchnic vascular bed was calculated on the basis of its arterial (A) and hepatic venous (HV) radioactivity: $f={ }^{14} \mathrm{C}$ $18: 1_{\mathrm{A}-\mathrm{HV}} /{ }^{14} \mathrm{C}-18: 1_{\mathrm{A}}$. The uptake of oleic acid ( $\mathrm{U}$, in micromoles per minute) by the splanchnic area was calculated as the product of $f$, the arterial plasma concentration of free oleic acid, and the splanchnic plasma flow (P). Release of oleic acid ( $R$, in micromoles per minute) was estimated as the difference between the uptake and the net exchange of unlabeled oleic acid: $R=U-\left(18: 1_{A-H V}\right) P(2,4)$.

Standard statistical methods were employed, using the paired $t$ test and an analysis of variance in analyzing changes from rest to exercise within each group, using an analysis of variance as well as the unpaired $t$ test in comparing the diabetic and control group during exercise and recovery, and by comparing linear regression lines (22). Data in the text, tables, and figures are given as mean \pm SEM

\section{Results}

Resting state. The arterial concentrations of substrates for diabetic patients and control subjects are given in Table II. The arterial glucose concentrations were measured on three occasions at 5-min intervals in all subjects in the resting state. The mean values obtained in the diabetics were $13.9 \pm 1.1,13.8 \pm 1.2$, and 
Table II. Arterial Concentrations of Substrates in Diabetic Patients (P) and Control Subjects (C) at Rest, during and after Exercise

\begin{tabular}{|c|c|c|c|c|c|c|c|c|c|}
\hline & & \multirow[b]{2}{*}{ Rest* } & \multicolumn{2}{|l|}{ Exercise } & \multicolumn{5}{|l|}{ Recovery } \\
\hline & & & $30 \mathrm{~min}$ & $60 \mathrm{~min}$ & $10 \mathrm{~min}$ & $20 \mathrm{~min}$ & $30 \mathrm{~min}$ & $45 \min$ & $60 \mathrm{~min}$ \\
\hline \multirow[t]{2}{*}{ FFA $(\mu \mathrm{mol} / \mathrm{l})$} & $\mathbf{P}$ & $967 \pm 110 \S$ & $1,073 \pm 102 \ddagger$ & $1,132 \pm 123 \ddagger$ & $1,617 \pm 64 \ddagger$ & $1,498 \pm 114 \ddagger$ & $1,279 \pm 125 \ddagger$ & $1,103 \pm 142 \ddagger$ & $1,163 \pm 152 \ddagger$ \\
\hline & $\mathrm{C}$ & $339 \pm 58$ & $519 \pm 79$ & $676 \pm 85$ & $1,120 \pm 172$ & $859 \pm 156$ & $642 \pm 113$ & $533 \pm 84$ & $576 \pm 95$ \\
\hline \multirow{2}{*}{$\begin{array}{c}\text { 3-OH-butyrate } \\
(\mu \mathrm{mol} / \mathrm{l})\end{array}$} & $\mathbf{P}$ & $810 \pm 171 \ddagger$ & $533 \pm 104 \ddagger$ & $656 \pm 110 \S$ & $1,089 \pm 154 \S$ & $1,260 \pm 139 \S$ & $1,339 \pm 168 \S$ & $1,369 \pm 205 \S$ & $1,384 \pm 212 \S$ \\
\hline & $\mathrm{C}$ & $38 \pm 6$ & $45 \pm 5$ & $89 \pm 18$ & $257 \pm 36$ & $300 \pm 36$ & $259 \pm 46$ & $190 \pm 46$ & $167 \pm 38$ \\
\hline \multirow{2}{*}{$\begin{array}{l}\text { Acetoacetate } \\
\qquad(\mu \mathrm{mol} / \mathrm{l})\end{array}$} & $\mathbf{P}$ & $306 \pm 50 \S$ & $208 \pm 34 \S$ & $259 \pm 36 \S$ & $360 \pm 53 \ddagger$ & $428 \pm 55 \ddagger$ & $431 \pm 58 \ddagger$ & $487 \pm 59 \S$ & $496 \pm 65 \S$ \\
\hline & $\mathrm{C}$ & $43 \pm 6$ & $33 \pm 4$ & $56 \pm 9$ & $108 \pm 6$ & $144 \pm 13$ & $135 \pm 23$ & $117 \pm 31$ & $108 \pm 26$ \\
\hline \multirow{2}{*}{$\begin{array}{l}\text { Glycerol } \\
(\mu \mathrm{mol} / \mathrm{l})\end{array}$} & $\mathbf{P}$ & $89 \pm 9 \S$ & $279 \pm 21 \S$ & $340 \pm 27 \ddagger$ & $226 \pm 17 \ddagger$ & $156 \pm 16 \ddagger$ & $111 \pm 18 \ddagger$ & $104 \pm 20 \ddagger$ & $124 \pm 25 \ddagger$ \\
\hline & $\mathrm{C}$ & $38 \pm 5$ & $134 \pm 18$ & $192 \pm 25$ & $138 \pm 22$ & $77 \pm 10$ & $49 \pm 7$ & $42 \pm 6$ & $52 \pm 10$ \\
\hline \multirow{2}{*}{$\begin{array}{l}\text { Glucose } \\
\qquad(\mathrm{mmol} / \mathrm{l})\end{array}$} & $\mathbf{P}$ & $13.8 \pm 1.1 \S$ & $13.9 \pm 1.3 \S$ & $13.2 \pm 1.5 \S$ & $13.7 \pm 1.3 \S$ & $13.9 \pm 1.3 \S$ & $13.4 \pm 1.4 \S$ & $13.9 \pm 1.3 \S$ & $13.9 \pm 1.4 \S$ \\
\hline & $\mathrm{C}$ & $4.4 \pm 0.1$ & $4.6 \pm 0.2$ & $4.5 \pm 0.2$ & $4.7 \pm 0.3$ & $4.6 \pm 0.2$ & $4.5 \pm 0.2$ & $4.6 \pm 0.2$ & $4.6 \pm 0.2$ \\
\hline
\end{tabular}

Means \pm SEM

* Data in the resting state were calculated from the mean of 2-3 observations obtained at 5-10-min intervals in each subject.

$\ddagger P$ vs. controls $<0.05$.

$\S P$ vs. controls $<0.01$.

13.8 $\pm 1.2 \mathrm{mmol} / \mathrm{l}$. Similarly, FFA, 3-hydroxybutyrate, acetoacetate, and glycerol concentrations measured at 10 -min intervals yielded mean values varying $<5 \%$, indicating a relatively steady state at rest with regard to the concentrations of circulating metabolites. Basal glucose, total ketone acids, FFA, and glycerol concentrations were, as expected, elevated in the diabetics in comparison with the controls.

Table III shows the arterial concentrations of glucagon, epinephrine, norepinephrine, and growth hormone. Arterial glucagon concentrations in the diabetics exceeded that of the con- trols. However, plasma epinephrine, norepinephrine, and growth hormone were comparable in the two groups. In Table IV, data on oleic acid turnover and splanchnic metabolism of oleic acid and ketones are shown. The arterial concentration as well as the total turnover of oleic acid was increased 2-3-fold in the diabetic group. Fractional turnover of oleic acid was not, however, altered in the diabetics.

The splanchnic uptake as well as the release of oleic acid was increased 2-4-fold in the diabetic group. The elevation in oleic acid uptake could not be attributed to an increased ex-

Table III. Arterial Concentrations of Glucagon, Epinephrine, Norepinephrine, and Human Growth Hormone (HGH) in Diabetic Patients $(P)$ and Control Subjects (C) at Rest, during and after Exercise

\begin{tabular}{|c|c|c|c|c|c|c|c|c|c|}
\hline & & \multirow[b]{2}{*}{ Rest* } & \multicolumn{4}{|l|}{ Exercise } & \multicolumn{3}{|l|}{ Recovery } \\
\hline & & & $15 \mathrm{~min}$ & $30 \mathrm{~min}$ & $45 \min$ & $60 \mathrm{~min}$ & $10 \mathrm{~min}$ & $30 \mathrm{~min}$ & $60 \mathrm{~min}$ \\
\hline \multirow{2}{*}{$\begin{array}{l}\text { Glucagon } \\
\qquad(p g / m l)\end{array}$} & $\mathbf{P}$ & $194 \pm 35 \ddagger$ & $204 \pm 47$ & $212 \pm 46$ & $214 \pm 48$ & $213 \pm 47$ & $219 \pm 41$ & $236 \pm 46$ & $220 \pm 44$ \\
\hline & $\mathrm{C}$ & $98 \pm 14$ & $101 \pm 16$ & $105 \pm 15$ & $107 \pm 15$ & $113 \pm 10$ & $119 \pm 14$ & $115 \pm 13$ & $102 \pm 14$ \\
\hline \multirow{2}{*}{$\begin{array}{l}\text { Epinephrine } \\
\qquad(p g / m l)\end{array}$} & $\mathbf{P}$ & $110 \pm 28$ & $158 \pm 41$ & $161 \pm 34$ & $185 \pm 32$ & $309 \pm 130$ & $110 \pm 20$ & $110 \pm 21$ & $114 \pm 27$ \\
\hline & $\mathrm{C}$ & $88 \pm 19$ & $147 \pm 38$ & $114 \pm 30$ & $161 \pm 44$ & $253 \pm 69$ & $96 \pm 27$ & $78 \pm 14$ & $95 \pm 21$ \\
\hline \multirow{2}{*}{$\begin{array}{l}\text { Norpinephrine } \\
\quad(p g / m l)\end{array}$} & $\mathbf{P}$ & $271 \pm 54$ & $1,093 \pm 180 \ddagger$ & $1,646 \pm 409 \ddagger$ & $1,339 \pm 281 \ddagger$ & $1,468 \pm 339$ & $534 \pm 104$ & $484 \pm 129$ & $387 \pm 73$ \\
\hline & $\mathrm{C}$ & $281 \pm 124$ & $476 \pm 43$ & $542 \pm 53$ & $635 \pm 83$ & $728 \pm 143$ & $303 \pm 49$ & $229 \pm 55$ & $240 \pm 63$ \\
\hline \multirow[t]{2}{*}{$\mathrm{HGH}(n g / m l)$} & $\mathbf{P}$ & $14 \pm 5$ & $15 \pm 4$ & $13 \pm 4$ & $11 \pm 3$ & $15 \pm 3$ & $10 \pm 2$ & $5 \pm 1$ & $3 \pm 1$ \\
\hline & $\mathrm{C}$ & $10 \pm 4$ & $9 \pm 3$ & $20 \pm 9$ & $23 \pm 10$ & $21 \pm 10$ & $13 \pm 5$ & $6 \pm 3$ & $3 \pm 1$ \\
\hline
\end{tabular}

* Data are given as mean $\pm \mathrm{SE}$.

$\ddagger P<0.05$ when compared with controls. 
Table IV. Arterial Concentration, Turnover, and Splanchnic Exchange of Oleic Acid and Ketone Acids in Diabetic Patients (P) and Controls $(C)$ at Rest and during Exercise*

\begin{tabular}{lllll}
\hline & & Rest & Exercise & \\
\hline Oleic acid concentration $(\mu \mathrm{mol} / \mathrm{l})$ & $\mathrm{P}$ & $375 \pm 50 \S$ & $422 \pm 55^{\|}$ & $\mathrm{ns}$ \\
& $\mathrm{C}$ & $129 \pm 25$ & $257 \pm 36$ & $P<0.001$ \\
Oleic acid turnover $(\mu \mathrm{mol} / \mathrm{min})$ & $\mathrm{P}$ & $360 \pm 47 \S$ & $595 \pm 70$ & $P<0.01$ \\
& $\mathrm{C}$ & $146 \pm 35$ & $404 \pm 74$ & $P<0.01$ \\
Fractional oleic acid turnover $\left(\mathrm{min}^{-1}\right)$ & $\mathrm{P}$ & $0.33 \pm 0.02$ & $0.51 \pm 0.04$ & $P<0.001$ \\
& $\mathrm{C}$ & $0.34 \pm 0.02$ & $0.53 \pm 0.03$ & $P<0.001$ \\
Splanchnic fractional uptake of oleic acid & $\mathrm{P}$ & $0.36 \pm 0.01$ & $0.45 \pm 0.02$ & $P<0.01$ \\
& $\mathrm{C}$ & $0.36 \pm 0.03$ & $0.43 \pm 0.03$ & $0.05<P<0.01$ \\
Splanchnic oleic acid uptake $(\mu \mathrm{mol} / \mathrm{min}$ ) & $\mathrm{P}$ & $111 \pm 16 \S$ & $82 \pm 15$ & $\mathrm{~ns}$ \\
& $\mathrm{C}$ & $40 \pm 7$ & $68 \pm 14$ & $P<0.05$ \\
Splanchnic oleic acid release $(\mu \mathrm{mol} / \mathrm{min})$ & $\mathrm{P}$ & $35 \pm 7 \S$ & $38 \pm 4$ & $\mathrm{~ns}$ \\
& $\mathrm{C}$ & $10 \pm 3$ & $31 \pm 4$ & $P<0.001$ \\
3-Hydroxybutyrate output $(\mu \mathrm{mol} / \mathrm{min})$ & $\mathrm{P}$ & $413 \pm 39 \S$ & $614 \pm 95 \S$ & $P<0.05$ \\
Acetoacetate output $(\mu \mathrm{mol} / \mathrm{min})$ & $\mathrm{C}$ & $39 \pm 10$ & $170 \pm 33$ & $P<0.01$
\end{tabular}

ns, not significant.

* Values are given as mean \pm SE.

¥ Significance of difference between rest and exercise values.

$\S P<0.01$ when compared with controls.

" $P<0.05$ when compared with controls.

T Oleic acid uptake was calculated as the product of the fractional uptake of oleic acid, the arterial concentration of oleic acid, and estimated hepatic plasma flow.

traction of oleic acid by the splanchnic bed, since its fractional extraction was identical in the patients and controls. On the other hand, oleic acid delivery to the splanchnic bed (arterial concentration $\times$ plasma flow) was increased in the diabetic group $(116 \pm 23$ vs. $308 \pm 38 \mu \mathrm{mol} / \mathrm{min}, P<0.05)$. Furthermore, as

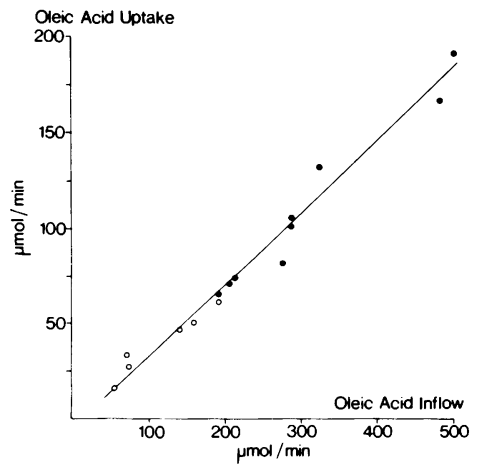

Figure 2. Splanchnic oleic acid uptake in relation to oleic acid inflow in the resting state in diabetic and control subjects. Oleic acid inflow is expressed as the product of estimated hepatic blood flow and arterial oleic acid concentration. Filled symbols represent diabetic patients and unfilled circles correspond to normal controls. The solid line denotes the regression line determined for all subjects $(\mathrm{Y}=0.38 \times-5.0, r$ $=0.98, P<0.001)$. shown in Fig. 2, a direct linear correlation was observed in both the diabetics and controls between splanchnic delivery (inflow) of oleic acid and its uptake by the splanchnic bed. The slope of the regression line was the same in the diabetics and controls.

The splanchnic production of ketone acids was markedly increased in the diabetics. Output of 3-hydroxybutyrate was increased 10-fold, while output of acetoacetate was increased 5-6-fold. As shown in Fig. 3, the proportion of splanchnic uptake of FFA that was converted to ketone acids was threefold greater in the diabetics. In the controls, only $20 \%$ of splanchnic FFA uptake could be accounted for as ketone body output, while in the diabetics this value rose to $61 \%$. Estimated hepatic blood flow was comparable in controls $(1,560 \pm 60 \mathrm{ml} / \mathrm{min})$ and diabetics $(1,520 \pm 100 \mathrm{ml} / \mathrm{min})$.

Leg exchange of oleic acid and ketones is shown in Table V. In the resting state there was a $67-100 \%$ increase in leg uptake and release of oleic acid in the diabetics. Fractional extraction of oleic acid was, however, lower in the diabetics as compared with controls. Uptake of both ketone acids by the leg was increased 5-6-fold in the diabetics. Uptake of ketone acids by the legs (both legs) could account for $22 \%$ of splanchnic ketone production in the diabetics and $32 \%$ in the controls. 

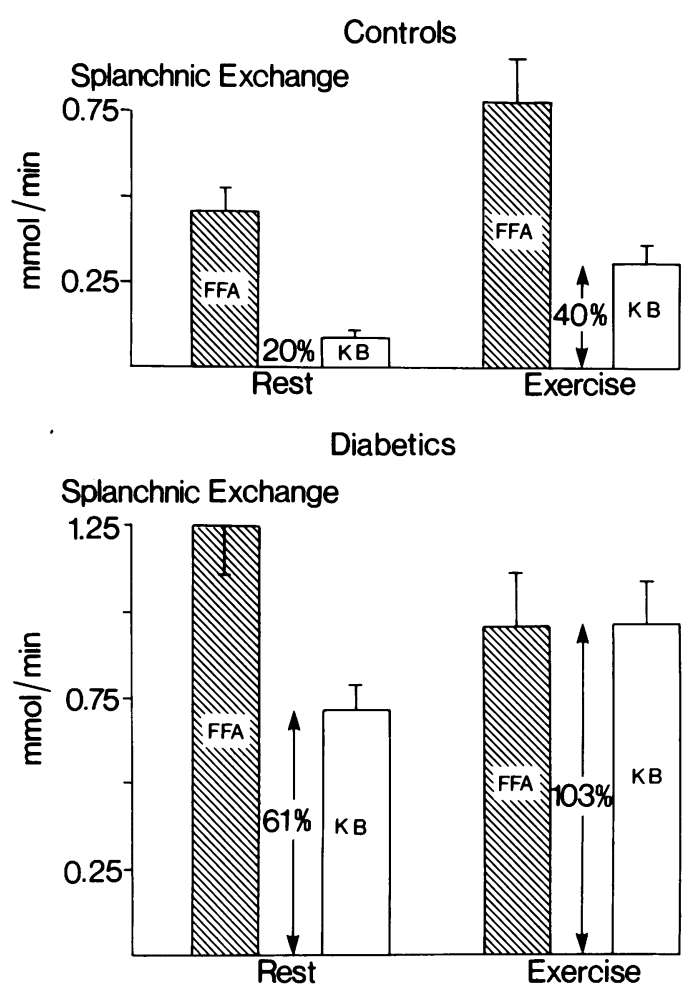

Figure 3. Splanchnic uptake of FFA and production of ketone bodies at rest (above) and during exercise (below). Splanchnic FFA uptake was calculated from oleic acid uptake and the percentage oleic acid in plasma FFA. For comparison with ketone body production it was converted into 4-carbon equivalents, assuming a mean chain length of 17.4 carbon atoms per fatty acid.

Exercise. During exercise, arterial concentrations (Table II) of FFA rose twofold $(P<0.001)$ while ketone acids increased $30-130 \%(P<0.05)$ in the controls (Table II). In contrast, in the diabetics, arterial FFA rose only $20 \%(P<0.05)$ while ketone acids fell by $20-30 \%(P<0.01)$. Nevertheless, arterial FFA and ketone acids remained markedly higher (2-10-fold) in the diabetic group $(P<0.001$ by analysis of variance [ANOVA]). In both groups, parallel 3-4-fold elevations in glycerol and unchanged concentrations of glucose were observed (Table II). Glycerol and glucose levels were thus significantly higher in the diabetics throughout exercise $(P<0.001$, by ANOVA).

Plasma glucagon and growth hormone (Table III) showed no significant increase in either group in response to exercise. In contrast, twofold increments in epinephrine were observed in both groups in response to exercise $(P<0.01)$. Plasma norepinephrine showed a twofold greater rise in the diabetics as compared with the controls (Table III). Plasma glucagon levels were also significantly higher in the diabetics during exercise $(P<0.02$ by ANOVA).

The arterial concentration and total turnover of oleic acid increased by 100 and $175 \%$, respectively, in the controls during exercise (Table IV) while the corresponding values for the diabetics were 15 and $65 \%$. The fractional turnover of oleic acid showed comparable increases in the diabetic and control groups in response to exercise (Table IV). Estimated hepatic blood flow fell by $35 \%$ in the controls (to $1,040 \pm 80 \mathrm{ml} / \mathrm{min}, P<0.001$ ) and by $50 \%$ in the diabetic subjects (to $755 \pm 30 \mathrm{ml} / \mathrm{min}$, $P<0.001$ ) during exercise.

The effect of exercise on splanchnic metabolism of oleic acid differed in the diabetic and control subjects (Table IV). While splanchnic uptake of oleic acid rose by $70 \%$ during exercise in the control group $(P<0.05)$, it tended to fall in the diabetics in response to exercise (Table IV). These differing responses to exercise were attributable to differences in splanchnic delivery (inflow) of oleic acid. In the control group, splanchnic delivery of oleic acid rose by $25 \%$ as compared with the resting state (148 \pm 24 vs. $116 \pm 23 \mu \mathrm{mol} / \mathrm{min}, P<0.05)$. In contrast, in the diabetics, splanchnic inflow of oleic acid declined below resting values $(178 \pm 27$ vs. $308 \pm 38 \mu \mathrm{mol} / \mathrm{min}, P<0.02)$. As in the resting state, in both the diabetics and controls, a direct linear correlation was observed between splanchnic delivery of oleic acid and its splanchnic uptake during exercise (Fig. 4). The slope of the regression line was the same for the diabetics and controls during exercise (Fig. 4). However, the regression line was steeper than that observed in the resting state (Fig. 2$)(P<0.05)$. In keeping with the latter finding, splanchnic fractional extraction of oleic acid rose by $20-25 \%$ during exercise in both controls and diabetics (Table IV).

Despite the differing responses in normals and diabetics with respect to splanchnic uptake and inflow of FFA, splanchnic production of ketones rose in both groups in response to exercise

Table V. Leg Exchange of FFA, 3-Hydroxybutyrate, Acetoacetate, and Oxygen in Diabetic Patients $(P)$ and Healthy Controls $(C)$ at Rest and during Exercise (Mean $\pm S E$ )

\begin{tabular}{lllll}
\hline & & Rest & $\begin{array}{l}\text { Exercise } \\
(60 \mathrm{~min})\end{array}$ & $P^{*}$ \\
\hline $\begin{array}{c}\text { Oleic acid uptake } \\
(\mu \mathrm{mol} / \mathrm{min})\end{array}$ & $\mathrm{P}$ & $50 \pm 5 \ddagger$ & $198 \pm 20 \S$ & $<0.001$ \\
Oleic acid release & $\mathrm{C}$ & $25 \pm 7$ & $139 \pm 16$ & $<0.001$ \\
$\quad(\mu \mathrm{mol} / \mathrm{min})$ & $\mathrm{C}$ & $55 \pm 5 \S$ & $94 \pm 14 \S$ & $<0.05$ \\
Fractional oleic acid & $\mathrm{P}$ & $0.34 \pm 0.03 \ddagger$ & $0.18 \pm 0.01$ & $<0.001$ \\
uptake & $\mathrm{C}$ & $0.51 \pm 0.02$ & $0.16 \pm 0.01$ & $<0.001$ \\
& & & & \\
3-Hydroxybutyrate & $\mathrm{P}$ & $66 \pm 8 \ddagger$ & $242 \pm 36 \ddagger$ & $<0.001$ \\
uptake $(\mu \mathrm{mol} / \mathrm{min})$ & $\mathrm{C}$ & $12 \pm 4$ & $28 \pm 6$ & $<0.05$ \\
Acetoacetate uptake & $\mathrm{P}$ & $86 \pm 20 \S$ & $78 \pm 44$ & $\mathrm{~ns}$ \\
$\quad(\mu \mathrm{mol} / \mathrm{min})$ & $\mathrm{C}$ & $16 \pm 4$ & $22 \pm 6$ & $\mathrm{~ns}$ \\
$\begin{array}{c}\text { Oxygen uptake } \\
(\mathrm{mmol} / \mathrm{min})\end{array}$ & $\mathrm{P}$ & $1.86 \pm 0.34$ & $38.4 \pm 2.4$ & $<0.001$ \\
& $\mathrm{C}$ & $2.16 \pm 0.16$ & $41.8 \pm 3.0$ & $<0.001$ \\
\hline
\end{tabular}

ns, not significant.

* Significance of difference between rest and exercise values.

$\ddagger$ Significantly different from control value, $P<0.01$.

$\S$ Significantly different from control value, $P<0.05$. 


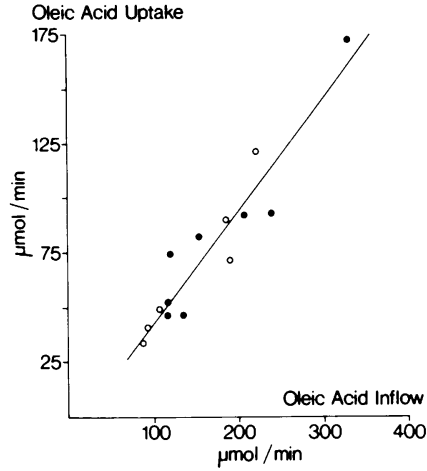

(Table IV). The augmented ketogenesis in the diabetic group was a consequence of increased intrahepatic conversion of FFA to ketones. During exercise, ketone production accounted for the entire splanchnic uptake of FFA (103\%), but accounted for only $60 \%$ of the uptake in the resting state (Fig. 3). In the control group, the fraction of FFA converted to ketones also rose above resting values, but to more than $40 \%$ (Fig. 3 ).

In Table $\mathrm{V}$, the effect of exercise on leg metabolism of oleic acid and ketones is shown. Uptake of oleic acid increased 4-5-fold in control and diabetic subjects despite a reduction in fractional extraction. Uptake of 3-hydroxybutyrate rose fourfold in the diabetics and twofold in the controls. Acetoacetate uptake was unchanged in both groups. Ketone acid uptake (assuming complete oxidation) could account for $<5 \%$ of leg oxygen uptake in the diabetics and $<1 \%$ in controls during exercise. Leg blood flow was $0.4 \pm 0.05 \mathrm{l} / \mathrm{min}$ in both patients and controls in the resting state and rose to $2.6 \pm 0.21 / \mathrm{min}$ in the diabetics and to $3.1 \pm 0.2 \mathrm{l} / \mathrm{min}$ in controls during exercise. Leg oxygen uptake rose $\sim 20$-fold during exercise (Table $\mathrm{V}$ ).

Recovery. During recovery from exercise (Table II), arterial FFA levels reached peak values at $10 \mathrm{~min}$ and remained elevated above basal at $60 \mathrm{~min}$ in the diabetics as well as in controls. In both groups, arterial ketone acids rose markedly in the first 10 min of recovery. Thereafter, there was a further rise in the diabetic group followed by a sustained elevation in ketone acids that persisted throughout the recovery period, so that total ketone acids at $60 \mathrm{~min}$ of recovery reached values of $1.9 \pm 0.3$ $\mathrm{mmol} / \mathrm{l}$. In contrast, in the control group, ketone acids reached peak values at $20 \mathrm{~min}$, declining thereafter by $25-30 \%$. As a result, the absolute difference in total ketone acid concentration between diabetics and controls was twofold greater at $60 \mathrm{~min}$ of recovery than during exercise (1.6 vs. $0.77 \mathrm{mmol} / \mathrm{l})$. Arterial norepinephrine levels also remained $50-100 \%$ above basal in the diabetics, but rapidly returned to baseline in the control group during recovery (Table III). The higher levels of plasma glucagon and norepinephrine observed in the diabetics during exercise also persisted in recovery (Table III, $P<0.01$ ) by ANOVA).

In the diabetics, splanchnic production of 3-hydroxybutyrate and acetoacetate rose $10-30 \%$ after the end of exercise $(P$ $<0.05-0.01)$ and remained elevated above the basal rate at 60 min of recovery (Fig. 5). In contrast, splanchnic production of ketone acids in the controls rose rapidly, to a peak value at 10 $\mathrm{min}$ after exercise, and declined rapidly between 20 and $30 \mathrm{~min}$ of recovery, reaching values twice the basal rate at $60 \mathrm{~min}$ of recovery (Fig. 5). As a result, the largest increment in splanchnic ketone production in the diabetics as compared with controls was observed at $60 \mathrm{~min}$ of recovery (Fig. 5).

\section{Discussion}

The rate of hepatic ketogenesis can be influenced by extrahepatic as well as hepatic processes. The extrahepatic processes include the rate of FFA release from adipose tissue (lipolysis) and the blood flow to the liver, which together determine the splanchnic inflow of FFA. The hepatic processes include the fractional extraction of FFA by the liver and the intrahepatic disposal of fatty acids (i.e., oxidation vs. reesterification with glycerol). The present study provides data on the relative importance of these varying processes in type I diabetes, during exercise and when diabetes and exercise are combined (Fig. 6).

The current data demonstrate that in the resting state the two major factors influencing the rate of ketogenesis are lipolysis and intrahepatic disposal of FFA. Splanchnic inflow of FFA was elevated in the diabetic group as a consequence of augmented net lipolysis (reflected by the combined elevation in arterial FFA and glycerol), inasmuch as estimated hepatic blood flow and fractional turnover of FFA were comparable in the two groups. In addition, the proportion of splanchnic FFA uptake attributable to ketone production was threefold greater in the diabetics. On the other hand, identical values for splanchnic fractional extraction of FFA (determined as oleic acid) were observed in the diabetics and controls. The present study thus provides evidence in intact humans that the role of the liver in enhancing ketogenesis in diabetes is by altering the fate of the extracted fatty acids rather than by increasing the extraction ratio of available fatty acids. This conclusion is further substantiated by the virtually identical regression lines for diabetic and normal subjects with respect to the relation between splanchnic inflow of

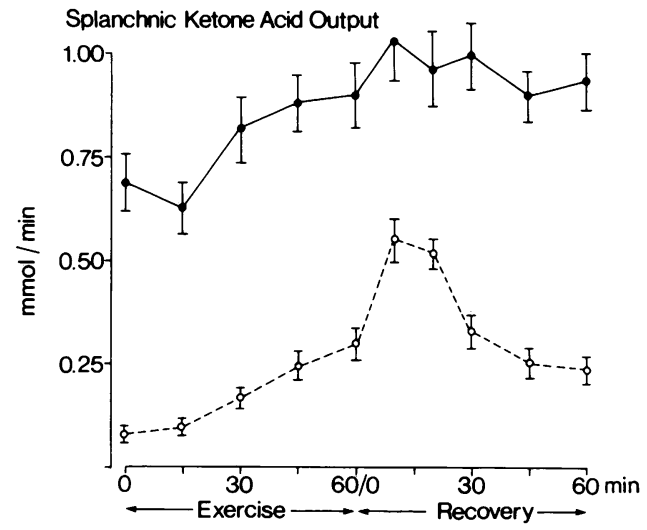

Figure 5. Splanchnic production of ketone acids in diabetic subjects (filled circles) and healthy controls (unfilled circles) during and after exercise. 


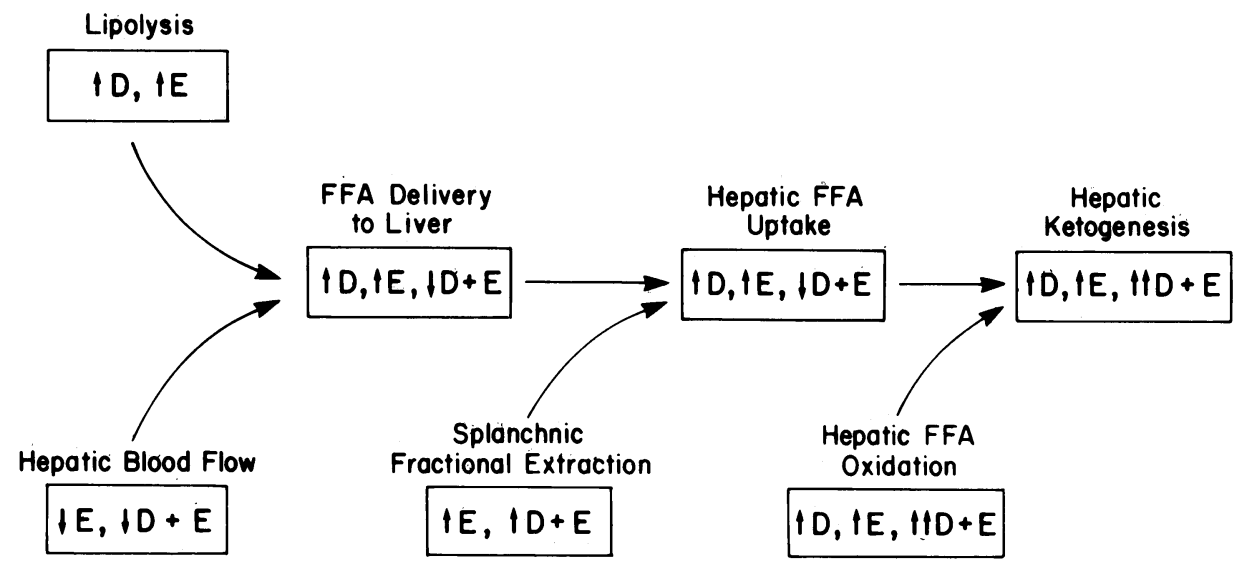

Figure 6. Regulatory sites in the control of ketogenesis. D, diabetes; E, exercise; $D+E$, exercise in diabetics; $\uparrow$, increase; $\downarrow$, decrease; $\uparrow$, marked increase. oleic acid and its uptake by the splanchnic bed. These findings are in strong agreement with the in vitro data of McGarry and Fóster (1) indicating that preferential utilization of FFA for oxidation is the major factor responsible for increased ketone formation in livers from diabetic animals.

In accord with earlier observations $(4,5)$, the diabetics showed an increase in ketogenesis in response to exercise. An acceleration in ketogenesis was also observed in the controls. The regulatory factors responsible for these exercise-induced increases showed similarities as well as differences when the diabetics and controls were compared. FFA delivery to the splanchnic bed continued to exert comparable effects on ketogenesis in the two groups, as reflected by the identical regression lines relating oleic acid inflow and its uptake by the splanchnic bed during exercise in the diabetics and controls (Fig. 3). In addition, in both groups, splanchnic fractional extraction of fatty acids rose above resting levels during exercise. Furthermore, the slope of the regression line relating splanchnic uptake of oleic acid to its inflow was significantly steeper during exercise than in the resting state. These findings indicate that in contrast to the effects of diabetes, the enhanced ketogenesis induced by exercise includes an increase in splanchnic fractional extraction of available FFA.

In contrast to the similarity of responses with respect to fractional extraction of FFA, exercise induced differing effects in the controls and diabetics with regard to splanchnic inflow and splanchnic uptake of FFA. Splanchnic uptake of FFA tended to fall during exercise in the diabetics. This decline was a consequence of a decrease in splanchnic inflow of FFA, which was attributable to a $50 \%$ reduction in estimated hepatic blood flow inasmuch as arterial FFA levels tended to rise by $15-20 \%$ in response to exercise in the diabetics. In contrast, in the normal subjects, a twofold increase in arterial FFA more than compensated for the reduction in hepatic blood flow so that splanchnic inflow of FFA and its uptake by the splanchnic bed rose as compared with the resting state.

Despite these differing effects of exercise on splanchnic FFA delivery in diabetic as compared with normal subjects, both groups responded to exercise with an increase in ketogenesis. In the diabetic group, this increase in ketone production was a consequence of a marked shift in the intrahepatic disposition of FFA. With regard to splanchnic balance of lipid substrates, it is noteworthy that during exercise the output of ketones by the diabetics corresponded to the entire splanchnic uptake of FFA. These findings thus indicate that the importance of increased hepatic oxidation of FFA as a determining factor in ketogenesis in the diabetic (1) is even further exaggerated when diabetes is combined with exercise.

The regulatory sites in the control of ketogenesis influenced by diabetes, exercise, and exercise combined with diabetes are summarized in Fig. 5. In diabetes, increased ketogenesis is attributable to augmented lipolysis (resulting in increased FFA delivery) and increased hepatic conversion (oxidation) of FFA to ketone acids. In exercise, increased ketogenesis is due to an augmentation in splanchnic fractional extraction of FFA in addition to increases in lipolysis and in intrahepatic conversion of FFA to ketones. Finally, when exercise and diabetes are combined, increased ketogenesis is due to augmented fractional extraction of FFA and to an even further increase in hepatic conversion of FFA to ketone acids.

Concerning the mechanisms of these changes in FFA and ketone metabolism, insulin lack and insulin lack plus glucagon excess, respectively, have been implicated in the increase in lipolysis and augmented hepatic oxidation of FFA, which occur in diabetes (1). The changes in lipolysis and in hepatic conversion of FFA to ketones associated with exercise may also be attributable to the hypoinsulinemia (23) and hyperglucagonemic (23) effects of exercise. Note, however, that plasma glucagon did not rise in either group in response to exercise, perhaps because of the low intensity of the exercise performed and because it was limited to only $1 \mathrm{~h}$ in duration (24). On the other hand, plasma catecholamines rose in response to the exercise and may have contributed to the augmented fractional extraction of FFA by the splanchnic bed, which was observed in the controls as well as in the diabetics in response to exercise. Furthermore, the exaggerated rise in plasma norepinephrine may have been a factor in the exaggerated increase in intrahepatic conversion of FFA to ketones, which was observed in the diabetic patients during exercise. The possibility also exists that catecholamines contributed to ketogenesis by increasing lipolysis of stored triglyceride in the liver. Previous studies have, in fact, suggested 
that an hepatic effect of norepinephrine is responsible at least in part for its action in enhancing ketogenesis (25). The exaggerated norepinephrine response to exercise observed in the current study is also in keeping with earlier findings in type I diabetics (26).

In a previous study we observed that the increase in ketogenesis induced by exercise in diabetics is dependent, in part, on the status of diabetic control before initiating the exercise (4). In those patients in whom arterial ketone acid levels exceeded $3.0 \mathrm{mmol} / \mathrm{l}$ at rest, a greater ketogenic effect was observed than in patients with ketone levels of $\leq 1.0 \mathrm{mmol} / \mathrm{l}(4)$. The present study did not include measurements of plasma C-peptide or free insulin to assess insulin availability in the diabetics. Nevertheless, the current observations provide evidence of complete conversion of splanchnic FFA uptake to ketones during exercise in subjects with ketone acid levels $<3.0 \mathrm{mM}(0.4-2.4 \mathrm{mmol} /$ l) in the resting state. These findings thus suggest that the augmentation in exercise-induced ketogenesis, which accompanies deteriorating control of diabetes (4), is likely to be a consequence of enhanced splanchnic inflow of FFA and/or increased splanchnic fractional extraction of FFA, rather than an increase in the proportion of FFA converted to ketones. In keeping with this conclusion, examination of the data from our earlier report (4) reveals that in patients with ketone acid levels $>3.0 \mathrm{mmol} /$ 1 in the resting state, splanchnic fractional extraction of FFA was greater than in the present study ( 78 vs. $45 \%$ ), while the proportion of FFA converted to ketones was comparable to the present findings (>90\%).

It should be noted that Sestoft et al. (3) failed to observe an increase in ketogenesis in either diabetic or control subjects in response to exercise. However, in that study, ketone production was evaluated after only 20 min of exercise, at which point arterial FFA levels had failed to rise above basal in either group (3). Their data on ketone production are also difficult to interpret, since their control subjects showed splanchnic production rates for ketone acids that were comparable to those of their diabetic subjects and 4-5-fold greater than we have observed in normal postabsorptive subjects in this or previous studies (2). Despite these differences, those authors also observed

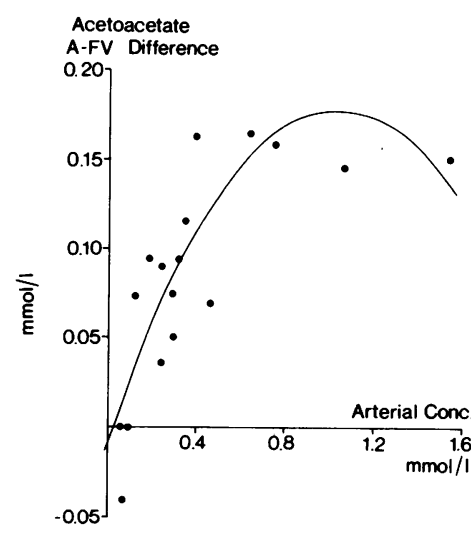

Figure 7. Arterio-femoral venous (A-FV) difference for acetoacetate in diabetic subjects in the resting state expressed as a function of its corresponding arterial concentration. The regression line represents the equation: $\mathrm{Y}=0.364$ $\times-0.175 \times-0.011(r$ $=0.86, P<0.001)$. Data from nine diabetic subjects in the current study have been combined with the values from eight diabetic subjects previously reported (4)
Figure 8. Arterio-femoral venous (A-FV) difference for 3-hydroxybutyrate in diabetic subjects in the resting state expressed as a function of its arterial concentrations. The regression line represents the equation: $\mathrm{Y}=0.247 \times-0.113$ $X+0.012(r=0.95, P$ $<0.001$ ). Data from nine diabetic subjects in the current study have been combined with the values from eight diabetic subjects previously reported (4).

a direct relation between splanchnic inflow and splanchnic uptake of FFA, and found evidence of a greater intrahepatic conversion of FFA to ketones in diabetics (3).

In an earlier study, with respect to ketone acid utilization, we observed linear regressions of the arterio-venous concentration differences for ketone acids across the forearm on their respective arterial concentrations in healthy subjects at rest (27). The regression coefficients were $\sim 0.5$ for both ketone acids. In the present study these observations have been extended into the range of ketone acid concentrations encountered in diabetic patients. By combining the current data with those from an earlier study of diabetic patients in whom higher ketone acid levels were found (4), this relation can be examined over a range of concentrations extending to $1.6 \mathrm{mmol} / \mathrm{l}$ for acetoacetate and $3.5 \mathrm{mmol} / 1$ for 3-OH-butyrate. It is then found that at high concentrations of the ketone acids, a better fit between arterial concentration and muscle uptake is obtained with curvilinear rather than linear regressions (Figs. 7 and 8). For arterial ketone concentrations in the normal range (below $0.3 \mathrm{mmol} / 1$ for 3 hydroxybutyrate and below $0.15 \mathrm{mmol} / 1$ for acetoacetate), the curved regressions are still rising steeply. These results, therefore, do not imply that there is a difference between diabetics and nondiabetics, but rather that at high ketone acid concentrations an additional factor that counteracts muscle uptake becomes increasingly important. The effect is more pronounced by 3 hydroxybutyrate than for acetoacetate (Figs. 7 and 8). Acetoacetate and 3-hydroxybutyrate are interconvertible in the mitochondria through the 3-hydroxybutyrate dehydrogenase reaction, and uptake of one of the acids should thus also be affected by the concentration of the other. In fact, the arterial-femoral venous difference for 3-hydroxybutyrate also fitted well to a multiple regression with arterial 3-hydroxybutyrate $\left(X_{1}\right)$ and arterial acetoacetate $\left(\mathrm{X}_{2}\right)$ as independent variables $(\mathrm{Y}=0.021$ $\left.\mathrm{X}_{1}-0.309 \mathrm{X}_{2}+0.151, r=0.74, P<0.01\right)$. The finding in the diabetics of a diminishing acetoacetate uptake and the transition from uptake to release of 3-hydroxybutyrate during rising ketone acid concentration is similar to what is observed during the hyperketonemia of progressive starvation $(28,29)$.

During exercise, a significant uptake of ketone acids by the leg muscles was observed in the controls, and was in keeping 
with earlier observations (4) on the diabetics. However, as a substrate for oxidative metabolism during exercise, ketone acid uptake is of minor importance. In the controls, it corresponded to $<1 \%$ of the leg oxygen consumption, and in the diabetics, accounted for $<5 \%$ of the oxygen consumption.

Despite the increase in ketogenesis that occurred during exercise, the hyperketonemic effect of exercise was not apparent in the diabetics until the postexercise recovery period. In fact, the largest increment in circulating ketones in the diabetics as compared with the control group was observed at $60 \mathrm{~min}$ of recovery. Previous studies have shown that the ketonemic effect of exercise in normal subjects is also marked in the recovery period (8). The current results indicate that the hyperketonemic response during recovery is not only greater but more sustained in type I diabetics. Moreover, our data demonstrate that this is caused by continued splanchnic overproduction of ketone acids in the diabetics throughout the recovery period, whereas in the controls, splanchnic ketone acid production rapidly declines after a peak at 10-20 min of recovery (Fig. 5). These findings thus suggest that the exercise-induced decompensation of diabetes that may occur when diabetics are poorly regulated in the resting state (4), may, with respect to blood ketone levels and ketogenesis, be more manifest in the postexercise recovery period.

\section{Acknowledgments}

Dr. Sato is the recipient of a grant from the Japanese Ministry of Education, Science, and Culture. The present study was supported by grants from the Swedish Medical Research Council (722 and 3108), the Petrus and Augusta Hedlund's Foundation, and the National Institutes of Health (AM 13526).

\section{References}

1. McGarry, J. D., and D. W. Foster. 1980. Regulation of hepatic fatty acid oxidation and ketone body production. Annu. Rev. Biochem. 49:395-420.

2. Hagenfeldt, L., A. Wennlund, P. Felig, and J. Wahren. 1981. Turnover and splanchnic metabolism of free fatty acids in hyperthyroid subjects. J. Clin. Invest. 67:1672-1677.

3. Sestoft, L., J. Trap-Jensen, J. Lyngsøe, J. P. Clausen, J. J. Holst, S. L. Nielsen, J. F. Rehfeld, and O. Schaffalitzky de Muckadell. 1977. Regulation of gluconeogenesis and ketogenesis during rest and exercise in diabetic subjects and normal men. Clin. Sci. (Mol. Med.). 53:411418.

4. Wahren, J., L. Hagenfeldt, and P. Felig. 1975. Splanchnic and leg exchange of glucose, amino acids and free fatty acids during exercise in diabetes mellitus. J. Clin. Invest. 55:1303-1314.

5. Berger, M., P. Berchtold, H. J. Cuppers, H. Drost, H. K. Kley, W. A. Muller, W. Wiegelmann, H. Zimmermann-Telschow, F. A. Gries, H. L. Kruskemper, and H. Zimmermann. 1977. Metabolic and hormonal effects of muscular exercise in juvenile type diabetics. Diabetologia. 13:355-365.

6. Rowell, L. B., J. R. Blackmon, and R. Bruce. 1964. Indocyanine green clearance and estimated hepatic blood flow during mild to maximal exercise in upright man. J. Clin. Invest. 43:1677-1690.

7. Horvath, S. M. 1979. Review of energetics and blood flow in exercise. Diabetes. 28(Suppl)1:33-38.

8. Johnson, R. H., J. L. Walton, H. A. Kregs, and D. H. Williamson. 1969. Post-exercise ketosis. Lancet. II:1383-1385.
9. Hagenfeldt, L., and J. Wahren. 1968. Human forearm muscle metabolism during exercise. II. Uptake, release, and oxidation of individual FFA and glycerol. Scand. J. Clin. Lab. Invest. 21:263-276.

10. Bradley, S. E. 1948. Measurements of hepatic blood flow. Methods Med. Res. 1:199-204.

11. Jorfeldt, L., and J. Wahren. 1971. Leg blood flow during exercise in man. Clin. Sci. Mol. Med. 41:459-471.

12. Dole, V. P., and H. Meinertz. 1960. Microdetermination of longchain fatty acids in plasma and tissues. J. Biol. Chem. 235:2595-2599.

13. Hagenfeldt, L. 1966. A gas chromatographic method for the determination of individual free fatty acids in plasma. Clin. Chim. Acta. 13:266-268.

14. Huggett, A. S. G., and D. A. Nixon. 1957. Use of glucose oxidase, peroxidase, and O-dianisidine in determination of blood and urinary glucose. Lancet. II:368-370.

15. Williamson, D. H., J. Mellanby, and H. A. Krebs. 1962. Enzymic determination of D-(-)-hydroxybutyric acid and acetoacetic acid in blood. Biochem. J. 82:90-96.

16. Wieland, O. 1962. Glycerin. In Methoden der Enzymatischen Analyse. H. V. Bergmeyer, editor. Verlag-Chemie, Weinheim, Federal Republic of Germany. 253-259.

17. Aquilar-Parada, E., A. M. Eisentraut, and R. H. Unger. 1969. Pancreatic glucagon secretion in normal and diabetic subjects. Am. J. Med. Sci. 257:415-419.

18. Rosselin, G., R. Assan, R. S. Yalow, and S. A. Berson. 1966. Separation of antibody-bound and unbound peptide hormones labeled with iodine-131 by talcum powder and precipitated silica. Nature (Lond.). 212:355-357.

19. Passon, P. G., and J. D. Peuler. 1973. A simplified radiometric assay for plasma norepinephrine and epinephrine. Anal. Biochem. 51:618-631.

20. Drabkin, D. L. 1950. Measurement of $\mathrm{O}_{2}$-saturation of blood by direct spectrophotometric determination. Methods Med. Res. 2:159161.

21. Drabkin, D. L., and J. H. Austin. 1935. Spectrophotometric studies. II. Preparations from washed blood cells; nitric oxide hemoglobin and sulfhemoglobin. J. Biol. Chem. 112:51-65.

22. Snedecor, G. W., and W. G. Cochran. 1967. Statistical Methods. Iowa State University Press, Ames, Iowa.

23. Felig, P., and J. Wahren. 1975. Fuel homeostasis in exercise. New Engl. J. Med. 293:1078-1083.

24. Ahlborg, G., P. Felig, L. Hagenfeldt, R. Handler, and J. Wahren. 1974. Substrate turnover during prolonged exercise in man: splanchnic and leg metabolism of glucose, free fatty acids and amino acids. J. Clin. Invest. 53:1080-1090.

25. Schade, D. S., and R. P. Eaton. 1979. The regulation of plasma ketone body concentration by counter-regulatory hormones in man. III. Effects of norepinephrine in normal man. Diabetes. 28:5-10.

26. Tamborlane, W. V., R. S. Sherwin, V. Koivisto, R. Hendler, M. Genel, and P. Felig. 1979. Normalization of the growth hormone and catecholamine response to exercise in juvenile-onset diabetic subjects treated with a portable insulin pump. Diabetes. 28:785-788.

27. Hagenfeldt, L., and J. Wahren. 1968. Human forearm muscle metabolism during exercise. III. Uptake, release and oxidation of $\beta$ hydroxybutyrate and observations on the $\beta$-hydroxybutyrate/acetoacetate ratio. Scand. J. Clin. Lab. Invest. 21:314-320.

28. Owen, O. E., and G. Reichard. 1971. Human forearm metabolism during progressive starvation. J. Clin. Invest. 50:1536-1541.

29. Hagenfeldt, L., and J. Wahren. 1971. Human forearm metabolism during exercise. VI. Substrate utilization in prolonged fasting. Scand. J. Clin. Lab. Invest. 27:299-306. 